\title{
Combined pH-impedance testing for reflux: current state of play and future challenges
}

\section{Santosh Sanagapalli, ${ }^{1}$ Rami Sweis ${ }^{2}$}

'Department of

Gastroenterology, St Vincent's Hospital Sydney, Darlinghurst, New South Wales, Australia

${ }^{2}$ GI Physiology Unit, University College London Hospital, London, UK

\section{Correspondence to}

Dr Santosh Sanagapalli, Department of Gastroenterology, St Vincent's Hospital Sydney, 390 Victoria St, Darlinghurst, NSW 2010, Australia;

santosh.sanagapalli@svha. org.au

Received 29 March 2017 Accepted 2 April 2017 Published Online First 21 April 2017

\section{SLinked}

http://dx.doi.org/10.1136/ flgastro-2016-100796

\section{CrossMark}

$$
\begin{aligned}
& \text { To cite: Sanagapalli S, } \\
& \text { Sweis R. Frontline } \\
& \text { Gastroenterology } \\
& \text { 2017;8:154-155. }
\end{aligned}
$$

It is now over 20 years since the introduction of multichannel intraluminal impedance monitoring (MII) in the oesophagus. ${ }^{1}$ Soon following, its application in children began in earnest with the widespread availability of paediatric catheters in 2002. MII detects oesophageal bolus movement by measurement of changes in electrical resistance and is used for assessment of reflux in tandem with $\mathrm{pH}$ monitoring (MII-pH). MII-pH heralded an advance in our ability to characterise reflux compared with the previous gold standard, $\mathrm{pH}$ monitoring alone. Advantages include the ability to detect nonacid and weakly acid reflux, distinguish between antegrade and retrograde bolus movements, differentiate liquid from gas reflux and assess proximal extent of the refluxate. In the intervening period, the translation of this more sophisticated and accurate measurement into improved patient outcomes has, however, not been as demonstrable as would have been hoped for.

The BSPGHAN position statement on MII-pH testing, published in the current issue of the journal, highlights the current state of the technology, practical advice for performance of investigations, as well as many issues and controversies that pertain to the use of the technology in the paediatric setting, and often equally to adult practice. ${ }^{2}$ The position statement, including its recommendations for practice, was formulated by consensus within a seven-member working group following literature review, but systematic evaluation of the quality of evidence supporting the recommendations was not reported. This probably reflects the low quality and lack of availability of evidence underpinning many of the recommendations.
The primary indication for MII-pH in both children and adults remains for the evaluation of refractory reflux symptoms. Its advantage over $\mathrm{pH}$ testing alone in this regard is to identify the significant minority of these patients whose symptoms are due to reflux of more than just liquid acid. ${ }^{3}{ }^{4}$ However, even when nonacid reflux is detected by MII, there is a paucity of evidence linking this finding with positive therapeutic outcomes; this fact applies equally to children and adults. ${ }^{5} 6$ In other words, MII-pH identifies more 'refluxers' who might have otherwise be considered functional in nature, but there is little evidence that these extra cases identified benefit from either optimised medical therapy or surgery. It is for this reason that the consensus of the US Esophageal Diagnostic Working Group was that there is insufficient evidence to justify antireflux surgery in adult patients who have an abnormal number of reflux events on MII-pH but no pathological oesophageal acid exposure. $^{7}$

In a similar fashion, the use of MII-pH in the evaluation of laryngopharyngeal and respiratory symptoms attributable to GORD has been extensively studied, but its precise role remains somewhat unclear. What is apparent is that there is a definite increase in diagnostic yield with the use of MII-pH compared with $\mathrm{pH}$ metry alone, ${ }^{89}$ and the increased yield is especially greater in the paediatric population where nonacid and proximal reflux detected by MII-pH seem to play an equally important role as acid reflux. ${ }^{7} 10$ The problem remains, however, that patients with cough attributed to nonacid reflux have poor outcomes from therapy, ${ }^{11}$ and therefore the consensus for 
adults with laryngopharyngeal symptoms is that antireflux surgery is only performed if there is evidence of excessive acid exposure in the distal oesophagus. ${ }^{7}$ The authors of the position statement recommend MII-pH to be used for a far wider variety of indications than would be acceptable in adults. This is reasonable given the greater diversity of manifestations of paediatric GORD, especially in infants, ${ }^{12}$ but it must be borne in mind that outcomes data are lacking.

The practice of paediatric medicine is inherently associated with its own unique challenges, and the use of MII-pH in children is no exception. Normal values for MII-pH have been derived from studies performed in healthy adults. ${ }^{1314}$ Since ethical considerations preclude the same in children, normal values have been derived from extrapolation from adults, as well as from children with GORD symptoms. However, the serious differences between children and adults are likely to impact on the validity of results. For example, positioning of the MII-pH catheter in children is commonly determined using radiology or body height-based calculations, though the validity of findings is suspect without confirmation of sensor positions. Manometric calculation of oesophageal length would be more accurate, but this is not always tolerated. Also, the algorithmic requirement of a drop in impedance across two sensors might not be transferable to children with smaller oesophageal length and width. Moreover, for obvious reasons, demonstration of symptom association might not be possible in a child. Finally, although normal values in adults are acquired unsedated, in children it is not uncommon for intubation to be performed under the influence of a sedative that may affect physiology.

These challenges suggest that results acquired are far from representative. As such, decisions leading to irreversible therapy, such as surgery, based solely on MII-pH findings in the absence of objective evidence of reflux such as florid oesophagitis, should always be taken with extreme caution. Although treatments are often aimed at alleviating symptoms in the child, it is important to remember that consequences of such decisions will persist into adulthood. Challenges such as these support the need to develop a more appropriate test that is fit for a child's stature and tolerability, with robust normal values for every age group being imperative to help guide therapy.

Competing interests None declared.
Provenance and peer review Commissioned; internally peer reviewed.

\section{REFERENCES}

1 Silny J. Intraluminal multiple electric impedance procedure for measurement of gastrointestinal motility. Neurogastroenterol Motility 1991;3:151-62.

2 Mutalib M, Rawat D, Lindley K, et al. BSPGHAN Motility Working Group position statement: paediatric multichannel intraluminal $\mathrm{pH}$ impedance monitoring-indications, methods and interpretation. Frontline Gastroenterology 2017.

3 Kline MM, Ewing M, Simpson N, et al. The utility of intraluminal impedance in patients with gastroesophageal reflux disease-like symptoms but normal endoscopy and 24-hour pH testing. Clin Gastroenterol Hepatol 2008;6:880.

4 Zerbib F, Roman S, Ropert A, et al. Esophageal pH-impedance monitoring and symptom analysis in GERD: a study in patients off and on therapy. Am J Gastroenterol 2006;101:1956-63.

5 Patel A, Sayuk GS, Gyawali CP. Acid-based parameters on $\mathrm{pH}$-impedance testing predict symptom improvement with medical management better than impedance parameters. Am J Gastroenterol 2014;109:836-44.

6 Rosen R, Levine P, Lewis J, et al. Reflux events detected by $\mathrm{pH}-\mathrm{MII}$ do not determine fundoplication outcome. J Pediatr Gastroenterol Nutr 2010;50:251-5.

7 Jobe BA, Richter JE, Hoppo T, et al. Preoperative Diagnostic Workup before Antireflux Surgery: An Evidence and Experience-Based Consensus of the Esophageal Diagnostic Advisory Panel. J Am Coll Surg 2013;217:586-97.

8 Blondeau K, Dupont LJ, Mertens V, et al. Improved diagnosis of gastro-oesophageal reflux in patients with unexplained chronic cough. Aliment Pharmacol Ther 2007;25:723-32.

9 Sifrim D, Dupont L, Blondeau K, et al. Weakly acidic reflux in patients with chronic unexplained cough during 24 hour pressure, $\mathrm{pH}$, and impedance monitoring. Gut 2005;54:449-54.

10 Rosen R, Nurko S. The Importance of Multichannel Intraluminal Impedance in the Evaluation of Children with Persistent Respiratory Symptoms. Am J Gastroenterol 2004;99:2452-8.

11 Francis DO, Goutte M, Slaughter JC, et al. Traditional reflux parameters and not impedance monitoring predict outcome after fundoplication in extraesophageal reflux. Laryngoscope 2011;121:1902-9.

12 Lightdale JR, Gremse DA. Gastroesophageal reflux: management guidance for the pediatrician. Pediatrics 2013;131:95.

13 Zerbib F, Roman S, Bruley Des Varannes S, et al. Normal values of pharyngeal and esophageal 24-hour $\mathrm{pH}$ impedance in individuals on and off therapy and interobserver reproducibility. Clin Gastroenterol Hepatol 2013;11:366-72.

14 Shay S, Tutuian R, Sifrim D, et al. Twenty-four hour ambulatory simultaneous impedance and $\mathrm{pH}$ monitoring: a multicenter report of normal values from 60 healthy volunteers. Am J Gastroenterol 2004;99:1037-43. 